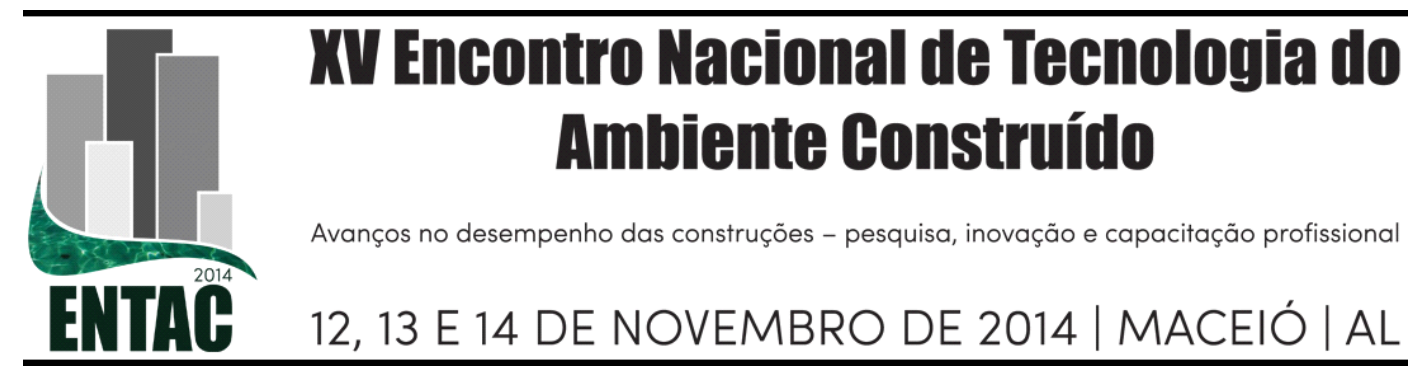

\title{
A INTRODUÇÃO DE ITENS DE FLEXIBILIDADE NO PROJETO DE EDÍFICIOS RESIDENCIAIS: O CASO DO EDF. VILLA VERDE EM MACEIÓ/AL
}

XAVIER, Regina do Nascimento Gomes (1); TOLEDO, Alexandre Márcio (2)

(1) Universidade Federal de Alagoas, e-mail: reginaxavier@gmail.com (2) Universidade Federal de Alagoas, e-mail: alexandre. toledo@,fau.ufal.br

\begin{abstract}
RESUMO
O processo de verticalização na cidade de Maceió/AL ocorreu tardiamente. Apenas na década de 1980 se consolidou a construção de edifícios multifamiliares e que seguiu as tendências do mercado imobiliário nacional. Quando surgem os itens de flexibilidade e como os usuários dos apartamentos se apropriam deles? O objetivo desse artigo é identificar os itens de flexibilidade adotados nos projetos de edifícios residenciais do período 1980-1985 e as formas de apropriação pelos usuários. Apresentam-se os resultados parciais de dissertação de mestrado em desenvolvimento no PPGAU/UFAL. A metodologia compreendeu identificação de itens de flexibilidade nos 55 edifícios multifamiliares aprovados pela Prefeitura nesse período, seguido de levantamentos fotográficos e entrevistas com moradores do Edf. Villa Verde. Os resultados apontam a presença de itens de flexibilidade pela primeira vez no período, mediante presença do banheiro reversível e do dormitório reversível em 7 edifícios. Destaca-se o fato de que a maioria dos entrevistados mantém a reversibilidade do ambiente. No entanto, o dormitório reversível possui caráter multiuso, pela proximidade com a área de serviço do apartamento, em substituição à antiga dependência de empregada. A presença dos itens de flexibilidade tem uma conotação positiva para os entrevistados, pois permitem algumas adaptações que não seriam possíveis sem os mesmos. A importância do estudo é o registro do momento em que os projetos de edifícios maceioenses passam a apresentar itens de flexibilidade, além de permitir a comparação em relação aos levantamentos de edifícios multifamiliares já realizados (década de 1960-1970) e em andamento (1986-1992), pelo Grupo de Estudos em Projeto de Arquitetura (gEPA/UFAL).
\end{abstract}

Palavras-chave: Flexibilidade, Ambiente Reversível, Edifícios Multifamiliares.

\begin{abstract}
The process of verticalization in Maceió / AL were late. Only in the 1980s consolidated the construction of multifamily buildings and have followed the trends of the national real estate market. Arise when items of flexibility and how users of the apartments appropriated them? The aim of this paper is to identify the items of flexibility adopted in the design of residential buildings of the period 1980-1985 and forms of ownership by users. Presents the partial results of dissertation in developing PPGAU / UFAL. The methodology included identification of items of flexibility in 55 multifamily buildings approved by the City in this period, followed by photographic surveys and interviews with residents of Edf. Green Villa. The results indicate the presence of items of flexibility in the first period by the presence of reversible bathroom and reversible in seven dormitory buildings. Noteworthy is the fact that the majority of respondents maintain reversibility of the environment. However, the reversible dorm has multipurpose character, the proximity to the service area of the apartment, replacing the old maid. The presence of items of flexibility has a positive connotation to the respondents, they allow some adaptations that would not be possible without them. The importance of the study is the record of the time the projects maceioenses buildings start to present items of flexibility, and allows a comparison with respect to withdrawals of multifamily buildings already made (decade of 1960 to 1970) and ongoing (1986-1992), the Group of Studies in Architectural Design (GEPA / UFAL).
\end{abstract}

Keywords: Flexibility, Reversible Spaces, Apartment Buildings 


\section{INTRODUÇÃO}

No Brasil, o termo "flexibilidade" começa a ser usado na década de 1980 para designar apartamentos que seriam mais adequados ao perfil do cliente e sua composição familiar. A tipologia do "terceiro opcional", como ficou conhecida, começava a garantir, no mercado imobiliário, o lugar de destaque absoluto que ocuparia ao longo de toda essa década, em apartamentos para todos os bolsos (VILLA; TRAMONTANO, 2000).

Na década de 1980, a percepção do desaparecimento da empregada doméstica residente junto à família, a tendência de diminuição do número de componentes familiares e a ideia de liberdade enquanto uso do apartamento por mais tempo contribuíram para que itens de flexibilidade tivessem maior inserção no mercado imobiliário.

Alguns autores corroboram essa tendência, a exemplo de Brandão (2006), que destaca o termo "habitação evolutiva" para definir a edificação em constante modificação ao longo de sua vida útil. A organização do espaço e o projeto devem ser compatíveis com diferentes padrões de vida no decorrer do tempo, ou seja, com multiplicidade de usos.

Segundo Villá (2008), um apartamento assim concebido podia alargar sua aceitação no mercado por permitir o crescimento do núcleo familiar e o uso confortável do apartamento por um tempo maior.

De acordo com Saleiro, Martins e Magalhães (2009), a flexibilidade no projeto varia no momento da modificação do ambiente reversível e a posição que o mesmo assume em relação aos demais setores do apartamento. Assim, um espaço é protagonista quando o ambiente é revertido e assume um papel diferenciado do uso original, agregando uma nomenclatura que o requalifica espacialmente, de maneira positiva. O espaço é coadjuvante quando no momento da modificação a nomenclatura será a mesma do compartimento que passou a ser incorporado e/ou atuará como um ambiente de apoio para o aposento considerado primário, podendo ter outra denominação.

Saleiro Filho (2009) define a "flexibilidade e suas variações nas plantas" mediante três propriedades: reversibilidade, permeabilidade e contiguidade, o que implica nas possibilidades de modificações que o projeto permite. Reversibilidade é a possibilidade de fazer a junção entre setores; permeabilidade permite transpassar, os espaços interagem por meio de acessos ou complementam-se os usos; contiguidade é a flexibilidade com viés geométrico, sem o acréscimo de acessos.

Em Maceió/AL, o processo de verticalização aconteceu de forma tardia, ganhando ritmo acelerado somente no início da década de 1980. De acordo com Barbosa (2009), além da arquitetura residencial, também era estimulado o turismo - Maceió foi denominada pelo marketing de "Paraíso das Águas". O resultado foi a implantação de grandes redes hoteleiras, cujas instalações também se davam por meio de edifícios verticais.

De acordo com Moreira (2012), em estudo sobre as tipologias dos edifícios multifamiliares construídos na capital alagoana no período de 1960-1970, à exceção de um dos projetos analisados (total de 35 edifícios), todos possuíam dependência completa de empregada, observando-se recorrência de reversibilidade desse ambiente.

$\mathrm{Na}$ década seguinte, verifica-se nos projetos de edifícios multifamiliares em Maceió/AL a tendência da implantação dos chamados "ambientes reversíveis", espaços com dois acessos, sendo um deles voltado para a área de serviço do apartamento e com característica multiuso: liberdade para o usuário definir a maneira como seria utilizado, em substituição da antiga dependência de empregada. Surgem, assim, o "terceiro reversível" que se posiciona como um "atalho" entre o setor íntimo e o setor de serviço. 
O Grupo de Estudos em Projeto de Arquitetura (FAU/UFAL) realiza, desde 2011, a pesquisa Avaliação do Desempenho Ambiental e Funcional de Unidades Habitacionais Unifamiliares e Multifamiliares em Maceió/AL, que resultou no levantamento de dados cadastrais de todos os projetos de edifícios multifamiliares aprovados pela Prefeitura de Maceió no período de 1960-1979, que culmina com a aprovação do Código de Edificações de 1979. Seguido do período de 1980-1985, que corresponde à aprovação do Plano Diretor de 1985. As análises resultaram em estudos de caracterização tipológica e topológica dos edifícios e apartamentos desses períodos. Atualmente, encontra-se em andamento o levantamento do período de 1986-1992.

Quais itens de flexibilidade são adotados no período de 1980-1985? Como eles são apropriados pelos usuários?

\section{OBJETIVO}

$\mathrm{O}$ artigo visa identificar os itens de flexibilidade adotados nos projetos dos edifícios residenciais multifamiliares do período de 1980 a 1985 e a forma de apropriação desses ambientes pelos usuários.

\section{METODOLOGIA}

A metodologia compreendeu identificação de itens de flexibilidade nos apartamentos dos 55 edifícios multifamiliares aprovados pela Prefeitura de Maceió no período de 1980-1985, seguido de entrevistas com 5 moradores e registro fotográfico da ocupação dos ambientes reversíveis do Edf. Villa Verde.

Dentre os 55 edifícios, identificaram-se em 7 edifícios com apartamentos com dormitório reversível e banheiro reversível.

O Edifício Villa Verde foi escolhido para análise por ser o único projeto com dormitório reversível e banheiro reversível. Projetado em 1985, localiza-se no bairro Ponta Verde, considerado de alto padrão aquisitivo na capital alagoana.

Figura 1 - Localização do Edifício Villa Verde na Cidade de Maceió/AL
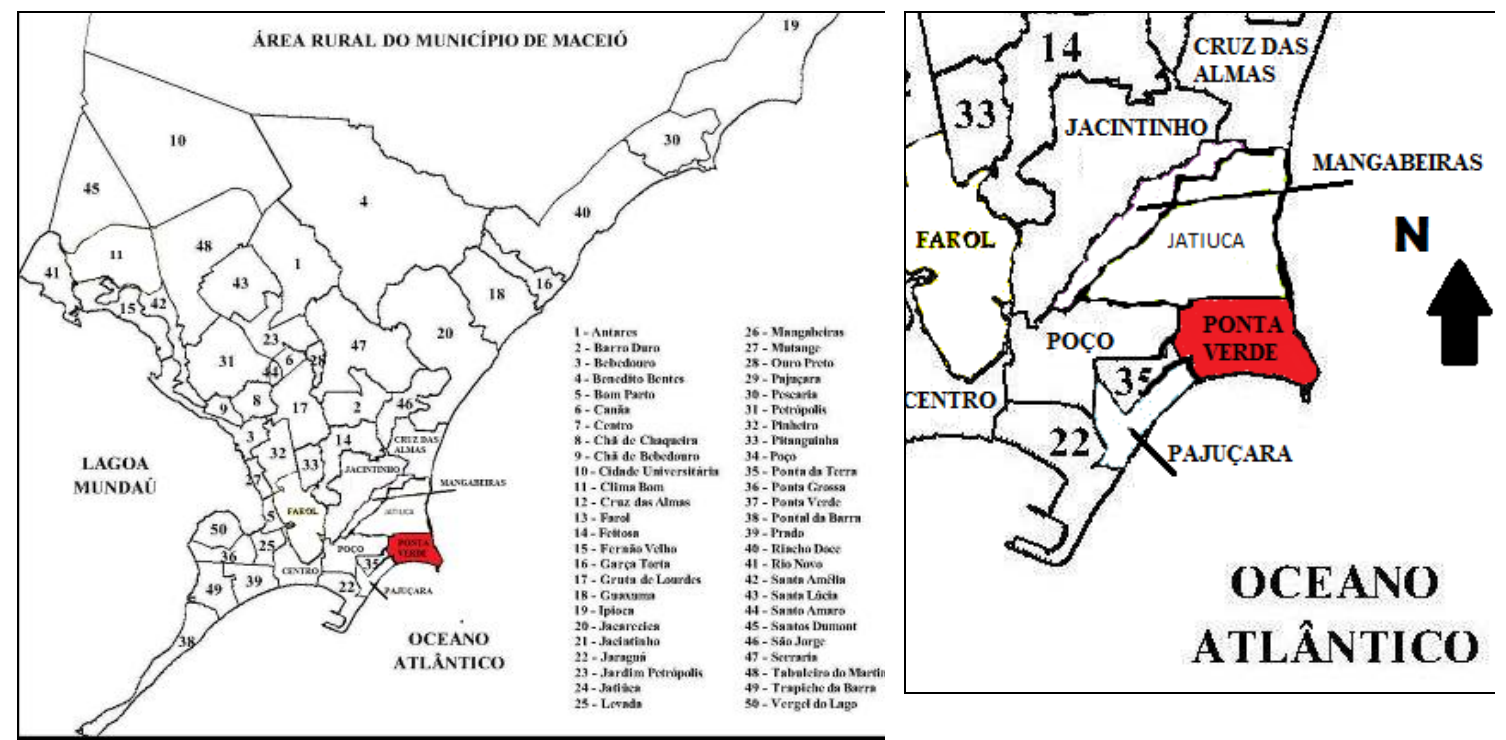

Fonte: Adaptado de Silva (2011) 
Com base nos estudos de Brandão (2002) e de Brandão e Heineck (2003) sobre flexibilidade, adotaram-se os seguintes critérios de análise: a) Presença de: (i) dormitório reversível; (ii) dependência de empregada; (iii) banheiro reversível; b) possibilidades de ampliação/uso simultâneo do ambiente.

Também se analisaram os ambientes reversíveis segundo Saleiro, Martins e Magalhães (2005), com ação protagonista ou coadjuvante.

Os questionários agruparam as perguntas em 3 blocos:

- Características dos moradores;

- Características do imóvel;

- Características da composição familiar e das etapas do ciclo de vida familiar.

Realizaram-se visitas in loco para registros fotográficos do edifício e dos ambientes reversíveis em situação atual. Os entrevistados foram escolhidos aleatoriamente, de acordo com a aceitação em participar da pesquisa e a permissão para o registro fotográfico do apartamento. Assim, os dados indicados pelas cinco famílias de moradores entrevistadas puderam ser confrontados com as imagens coletadas.

$\mathrm{Na}$ análise, os moradores serão identificados por números, em respeito ao código de ética em pesquisa. Os resultados serão demonstrados por meio de esquemas em planta baixa.

\section{ANÁLISE DOS RESULTADOS}

No projeto do Edf. Villa Verde destaca-se a presença de um dormitório reversível e um banheiro reversível. Os acessos aos ambientes reversíveis estão indicados por setas vermelhas (Figura 1):

\section{Figura 1 - Ambientes Reversíveis do Edf. Villa Verde}

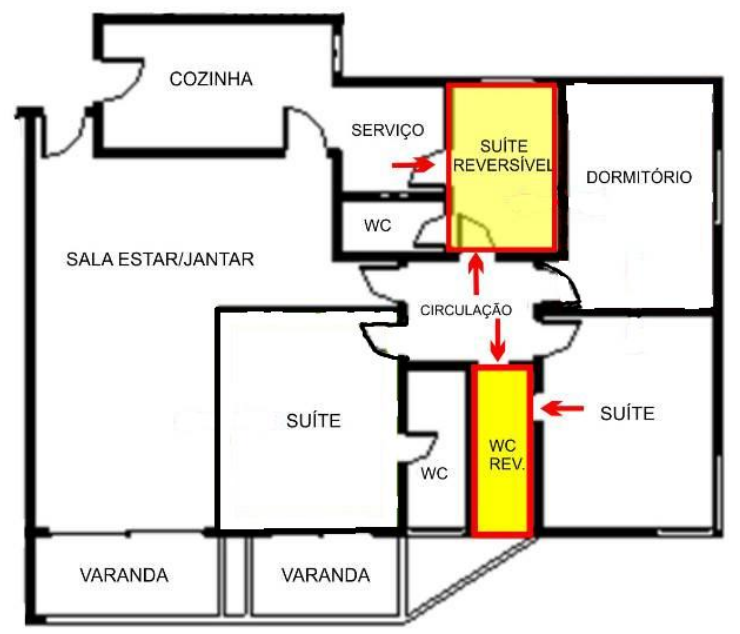

Fonte: adaptado pela autora, 2014.

Nota-se que o dormitório reversível foi posicionado entre o setor íntimo e o de serviço, em substituição à antiga dependência de empregada. Além disso, o acesso à circulação permite a possibilidade de livre escolha do uso desse ambiente, que possui caráter multiuso, portanto, flexível. A presença dos itens de flexibilidade tem uma conotação 
positiva para os entrevistados, pois permitem algumas reformas que não seriam possíveis sem os mesmos.

A setorização do apartamento do Villa Verde (Figura 2) demonstra que a suíte reversível, antiga dependência de empregada, apresenta característica de "permeabilidade" com a área de serviço. Os usos se complementam, pois fica nítida a possibilidade de escolha sobre qual setor o ambiente será inserido, conferindo caráter de "reversibilidade". A presença de um banheiro no dormitório reversível e sua ligação direta (ação protagonista) confere um caráter de setor íntimo ao espaço, mas sua relação com o setor de serviço não fica descartada.

Figura 2 - Setorização do Edf. Villa Verde

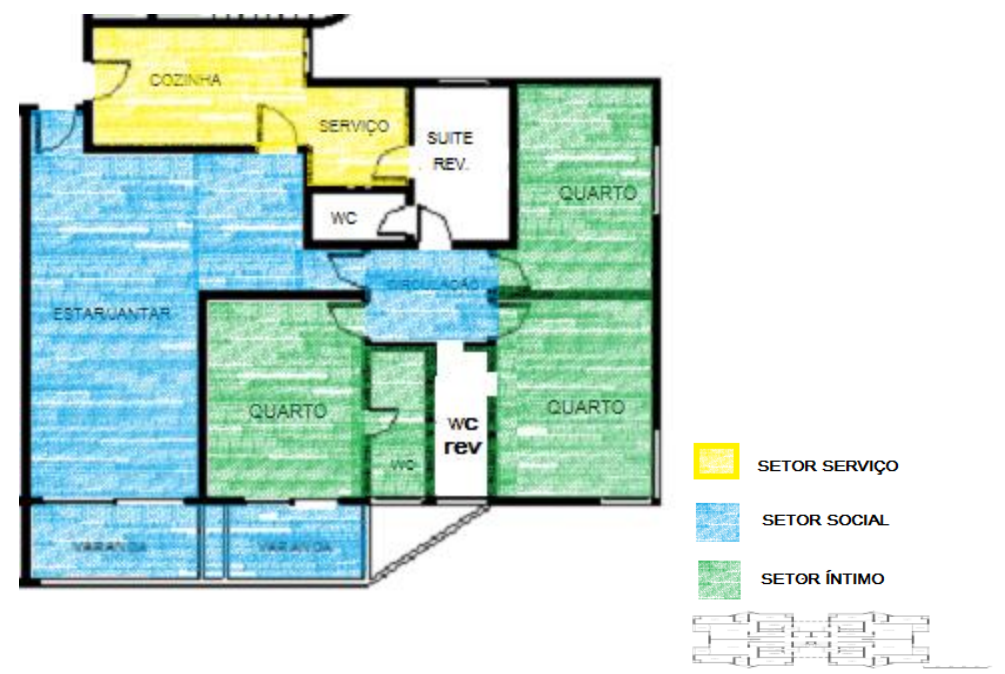

Fonte: adaptado pela autora, 2014.

Vale destacar que o banheiro reversível possui ação "coadjuvante" com o dormitório, pois serve de apoio em função de suíte e sua característica de "reversibilidade" permite a ligação entre os setores social e íntimo, por ser utilizado como banheiro social simultaneamente.

A suíte, que fica vizinha à sala de estar/jantar, apresenta nítido caráter de “contiguidade". Além disso, observa-se a possibilidade de "ação coadjuvante" em relação ao setor social, porque pode acrescentar usos ao mesmo, a exemplo de uma ampla sala de televisão ou escritório.

No momento da aplicação dos questionários, as informações relevantes apresentadas pelos moradores foram registradas como observação, além das perguntas e respostas definidas na ficha (Quadro 1).

Pode-se observar que houve uma média de 3 moradores por apartamento, de um total de 16 apartamentos do edifício. A média de tempo que essas famílias residem no imóvel segue uma média de 12 anos, o que garante que as modificações e o processo de adaptação estão consolidados.

Além disso, todos os entrevistados possuem imóvel próprio, conferindo caráter de estabilidade do imóvel. Apenas um morador respondeu que a presença do ambiente reversível foi irrelevante na aquisição do imóvel, já que herdou o imóvel de um parente. 


\section{Quadro 1 - Informações coletadas nos questionários}

\begin{tabular}{|c|c|c|c|c|}
\hline Morador & $\begin{array}{c}\text { Reside no } \\
\text { edf. (tempo) }\end{array}$ & $\begin{array}{c}\mathbf{N}^{\mathbf{0}} \\
\text { Moradores/ } \\
\text { apto }\end{array}$ & $\begin{array}{c}\text { Composição } \\
\text { familiar }\end{array}$ & $\begin{array}{c}\text { Realizou } \\
\text { modificação no } \\
\text { ambiente reversível }\end{array}$ \\
\hline 1 & 20 anos & 4 & Casal/2 filhos & SIM \\
\hline 2 & $3 a n o s$ & 3 & Casal/1 filho & SIM \\
\hline 3 & 7 anos & 4 & Casal/1 filho/1babá & NÃO \\
\hline 4 & 17 anos & 3 & Casal/1filho & NÃO \\
\hline 5 & 15 anos & 3 & Mãe/2filhos & SIM \\
\hline
\end{tabular}

Fonte: Adaptado pela autora, 2014.

É necessário ressaltar que se considerou como modificação do ambiente reversível, aqueles nos quais os moradores retiraram um dos acessos, transformando o dormitório em espaço independente. A vedação do acesso com móveis ou painel de madeira também é considerado modificação, pois impede o caráter reversível.

Verificaram-se diversas atividades atribuídas ao dormitório reversível (Quadro 2). Se, porventura, o morador realizou modificações nos demais ambientes do imóvel, não fazem parte do escopo do estudo.

\section{Quadro 2 - Atividades identificadas nos ambientes reversíveis}

\begin{tabular}{|c|c|c|c|c|}
\hline $\mathbf{N}^{\mathbf{o}}$ & $\begin{array}{c}\text { Realizou } \\
\text { modificação } \\
\text { no dormitório } \\
\text { reversível }\end{array}$ & $\begin{array}{l}\text { Contrata } \\
\text { empregada ou } \\
\text { diarista }\end{array}$ & $\begin{array}{l}\text { Função do } \\
\text { ambiente } \\
\text { reversível }\end{array}$ & Atividades identificadas \\
\hline 1 & SIM & SIM (não dorme) & Quarto de empregada & $\begin{array}{c}\text { Passar ferro em roupas } \\
\text { Descanso da empregada } \\
\text { Depósito }\end{array}$ \\
\hline 2 & SIM & SIM (dorme) & Quarto de empregada & $\begin{array}{c}\text { Dormir } \\
\text { (empregada dorme no trabalho) }\end{array}$ \\
\hline 3 & NÃO & SIM (não dorme) & Quarto da cunhada & $\begin{array}{l}\text { Ambiente de hóspede (cunhada) } \\
\text { Escritório/ Depósito } \\
\text { (babá utiliza dorm. da criança) }\end{array}$ \\
\hline 4 & NÃO & SIM (não dorme) & $\begin{array}{l}\text { Biblioteca/ } \\
\text { Escritório }\end{array}$ & $\begin{array}{l}\text { Ouvir música/ Leitura } \\
\text { Descanso/ Depósito }\end{array}$ \\
\hline 5 & SIM & NÃO (Diarista) & Quarto de empregada & $\begin{array}{c}\text { Depósito } \\
\text { Descanso da empregada }\end{array}$ \\
\hline
\end{tabular}

Fonte: Adaptado pela autora, 2014.

A função do ambiente reversível indica a denominação dada pelo entrevistado para o espaço multiuso. As atividades identificadas consideram-se aquelas presentes nos registros fotográficos, mesmo que não tenham sido citadas (presença de móveis, objetos, vestígios). 
As mudanças em relação à presença da empregada doméstica se restringiram ao fato de que nem sempre a mesma dorme no local de trabalho. Apenas um morador possui empregada doméstica que reside no emprego. As demais dispõem de uma cama para descanso, mesmo que o mesmo espaço sirva de depósito (Figura 3).

A dependência de empregada se posiciona como espaço de ligação direta entre o setor de serviço e o social, provavelmente para facilitar o trabalho da empregada doméstica. Nota-se também que a dependência é implantada distante do setor íntimo, exceção presente no Edf. Villa Verde.

Percebe-se ainda a presença da família nuclear tradicional em todos os apartamentos visitados.

\section{Figuras 3 - Atividades Identificadas no Dormitório Reversível}

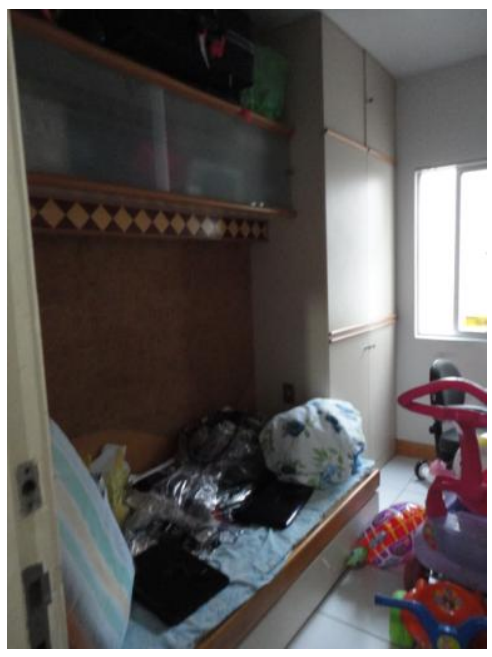

Quarto da Cunhada

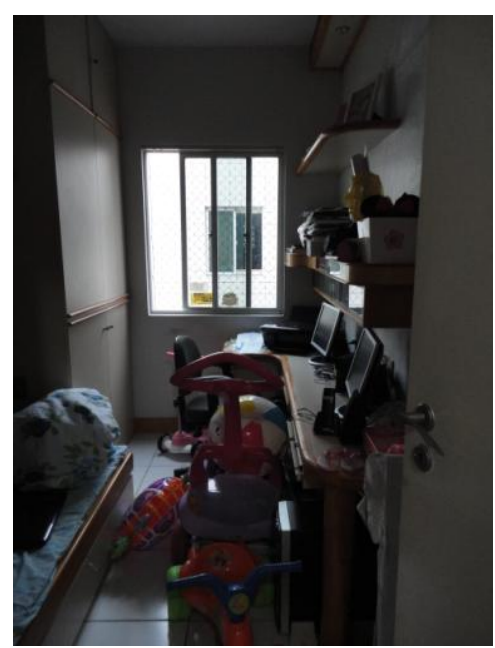

Depósito/Escritório

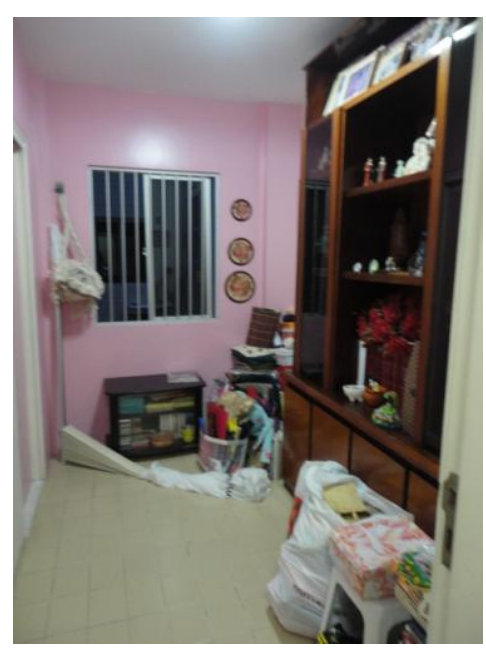

Biblioteca/descanso

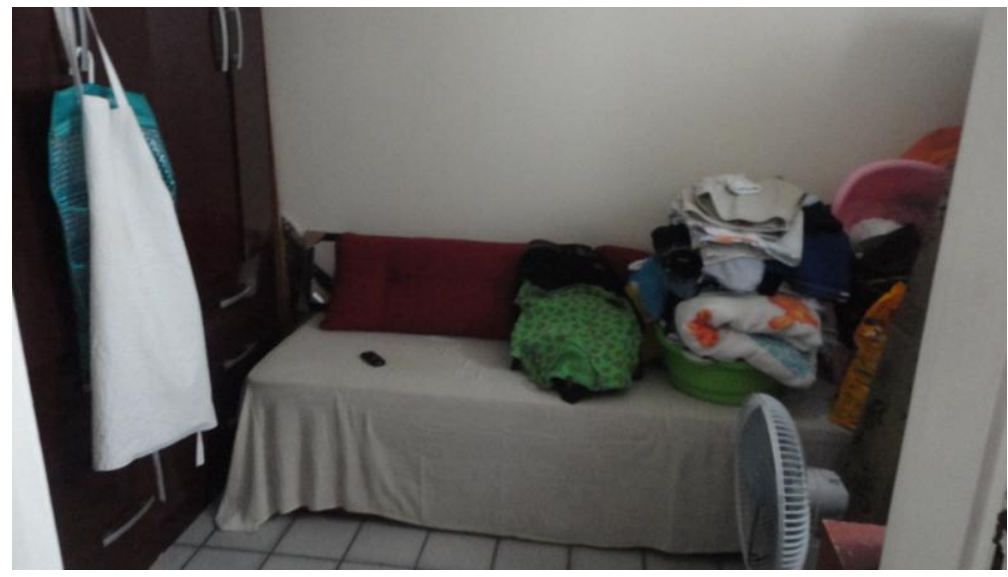

Quarto de empregada

Fonte: acervo pessoal, 2014.

O banheiro reversível não apresentou modificações significativas. Pode-se observar que o local que possui vedação ou teve a porta retirada do ambiente reversível recebeu uma determinada função (Figuras 4 e 5), em geral, ampliaram as circulações.

O objetivo dos moradores que eliminaram a duplicidade de uso do banheiro foi manter apenas a função de banheiro social e para preservar a privacidade da família. 
Figura 4 - Locais com acessos vedados e que receberam novos usos (circulação)

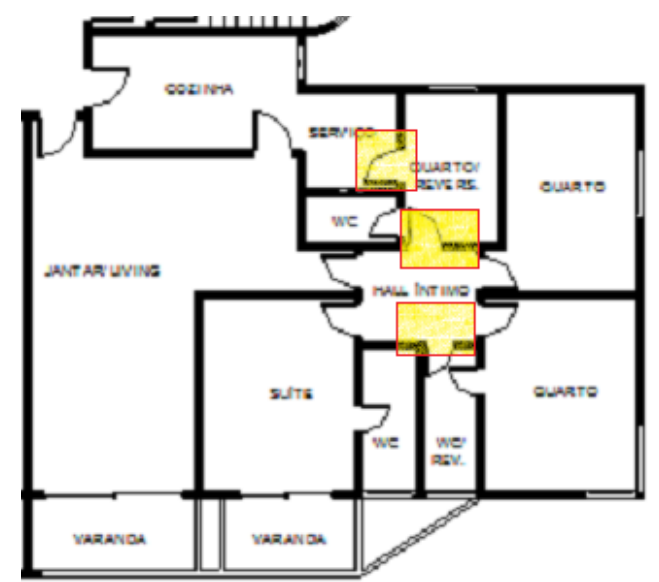

Fonte: adaptado pela autora, 2014.

Figuras 5 - Atividades encontradas na circulação

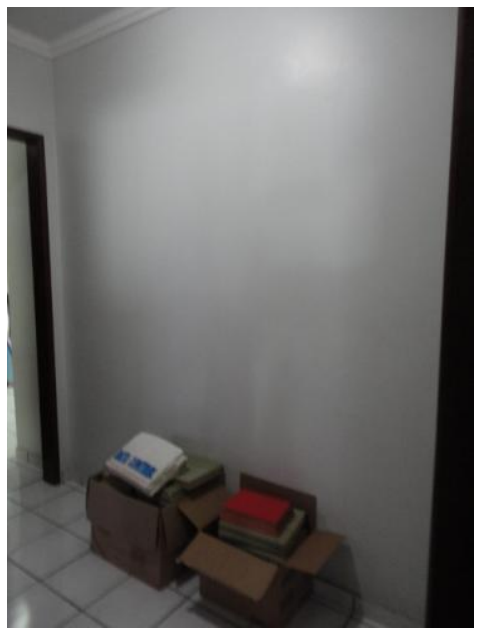

Depósito de objetos

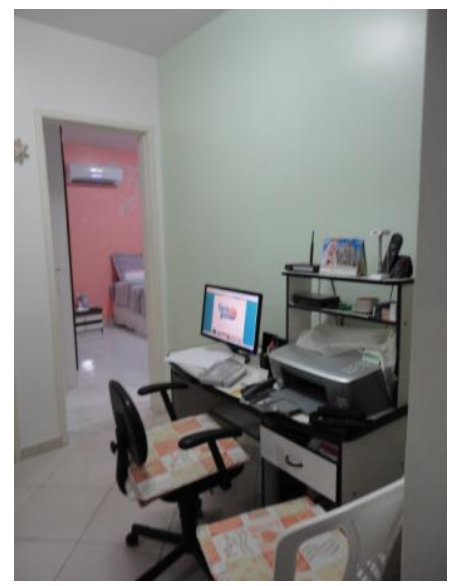

Escritório

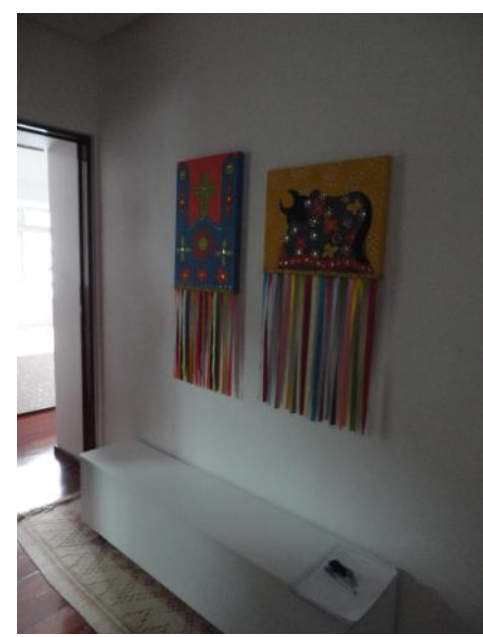

Obras de arte e puff

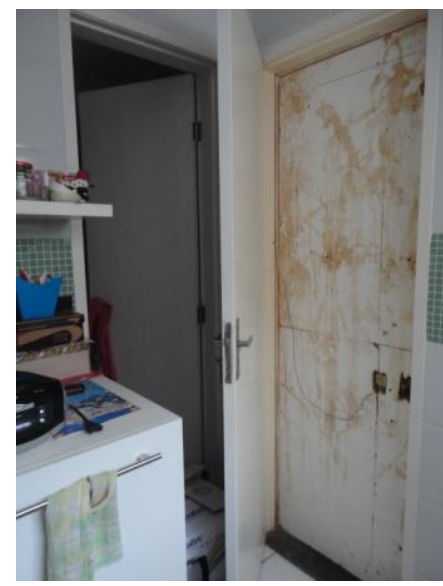

Acesso vedado com madeira

Fonte: acervo pessoal, 2014. 


\section{CONSIDERAÇÕES FINAIS}

Neste artigo, que teve como objetivo identificar itens de flexibilidade e formas de apropriação dos ambientes pelos usuários em apartamentos de edifícios do período de 1980-1985 na cidade de Maceió, por meio de levantamento fotográfico in loco e aplicação de questionário com os moradores, utilizou como objeto de estudo o Edifício Villa Verde, datado de 1985.

$\mathrm{O}$ desenvolvimento de habitações adequadas a diversos tipos familiares configurou-se como o principal ensejo para a realização do estudo. De certo modo e mais uma vez é apagar, de vez, a ideia de que as habitações podem ser concebidas, apenas, como soluções funcionais, elou que essa possibilidade é algo que pode ser, até, considerado como um aspeto positivo na concepção (COELHO, 2014).

A introdução do terceiro reversível é o item diferencial nos projetos de edifícios multifamiliares no período de 1980-1985, na cidade de Maceió. A pequena quantidade de edifícios encontrados que adotaram os dormitórios reversíveis no projeto não é marcante para consolidar o elemento na primeira metade da década de 1980 em Maceió. Porém percebe-se que foi o início de um relaxamento da setorização rígida, muito presente nos produtos imobiliários das décadas de 1960 e 1970.

A presença de 4 dormitórios, com 3 deles podendo se transformar em suítes, mantém o projeto do Villa Verde de acordo com necessidades atuais, mesmo após 29 anos de implantação. A possibilidade que a presença de um ambiente reversível agrega ao apartamento fica nítida como elemento de satisfação dos moradores, que residem no edifício em uma média de 12 anos.

As modificações presentes nos dormitórios reversíveis, a exemplo do fechamento do acesso pelo setor íntimo possui ação coadjuvante, porque o isola e posiciona como apoio do setor de serviço (depósito, quarto da empregada doméstica).

A reversibilidade com ação protagonista destaca-se nos apartamentos que inserem o dormitório plenamente ao setor íntimo (quarto da cunhada e biblioteca), agrega-se um valor positivo ao dormitório reversível.

Considerou-se também o posicionamento dos ambientes em relação aos demais e as possibilidades de conexões entre cômodos suportadas pela configuração espacial do apartamento. O que chama a atenção é que isso influencia diretamente nas possibilidades de uso que o projeto permite aos usuários.

Conclui-se, dessa maneira, que apesar de ter sido o primeiro edifício com essa tipologia, são evidentes elementos que indicam mudanças na oferta de edifícios em Maceió, apesar do predomínio de exemplares que atendiam a uma família nuclear e repetiam, por vezes, a tripartidação presente em residências unifamiliares.

\section{REFERÊNCIAS}

BRANDÃO, Douglas Queiroz; HEINECK, Luiz Fernando Mählmann. Significado multidimensional e dinâmico do morar: compreendendo as modificações na fase de uso e propondo flexibilidade nas habitações sociais. Ambiente Construído, Porto Alegre, v. 3, n.4, 2003.

BRANDÃO, Douglas Queiroz. Diversidade e potencial de flexibilidade arranjos espaciais de apartamentos: uma análise do produto imobiliário no Brasil. 2002. Tese (Doutorado em Engenharia de Produção) - Programa de Pós-Graduação em Engenharia de Produção. Universidade Federal de Santa Catarina. Florianópolis, 2002. 
Habitação social evolutiva: aspectos construtivos, diretrizes para projetos e proposição de arranjos espaciais flexíveis. Cuiabá: CEFETMT, 2006.

COELHO, Antonio Baptista. Mundos domésticos e pessoais: habitação e espaços da habitação. Artigo XLIV. Ano X. no 469. Lisboa, 2014. Acesso em: http://infohabitar.blogspot.pt em maio/2014.

MOREIRA, Maria Elisa. O início da verticalização em Maceió-AL: um estudo tipológico dos edifícios multifamiliares em altura (1960-1970). 2012. Dissertação (mestrado em Arquitetura e Urbanismo: Dinâmicas do Espaço Habitado). Universidade Federal de Alagoas. Faculdade de Arquitetura e Urbanismo. Maceió, 2012.

SALEIRO, Mario O. ; MARTINS, Elizabete R. de C. ; MAGALHÃES, Fernanda. Adaptabilidades espaciais nas habitações multifamiliares na cidade do Rio de Janeiro- $O$ processo de reversibilidade do quarto de empregado. Cadernos do PROARQ/ UFRJ/ Programa de Pós-Graduação em Arquitetura da Universidade Federal do Rio de Janeiro. Vol 9. $\mathrm{n}^{\circ}$ 9. Rio de Janeiro: UFRJ/ PRAORQ, 2005.

SALEIRO FILHO, Mário de Oliveira. A arquitetura na anarquitetura: os conceitos de flexibilidades espaciais na produção imobiliária na cidade do Rio de Janeiro. Tese de Doutorado do Programa de Pós-Graduação em Arquitetura. Universidade Federal do Rio de Janeiro. Rio de Janeiro: UFRJ/FAU/PROARQ, 2009.

SILVA, Jordânnya D. do N. Urbanização e saúde em Maceió, AL: o caso dos bairros Vergel do Lago, Jacintinho e Benedito Bentes. Dissertação (mestrado em Arquitetura e Urbanismo: Dinâmicas do Espaço Habitado). Universidade Federal de Alagoas. Faculdade de Arquitetura e Urbanismo. Maceió, 2011.

VILLA, S. B; TRAMONTANO, M. Apartamento metropolitano, evolução tipológica. In: $\mathbf{6}^{\mathbf{0}}$ seminário de história da cidade e do urbanismo- 5 séculos de cidades no Brasil, Natal, 2000.

VILLÁ, Joan. Flexibilidade, exigência do habitat contemporâneo. In: $4^{\mathbf{0}}$ Forum de Pesquisa da FAU-Mackenzie, 2008, São Paulo. $4^{\circ}$ Forum de Pesquisa da FAU-Mackenzie, 2008. 